\title{
A PERVERSA CONCENTRAÇÃO DE RENDA VIA SISTEMA TRIBUTÁRIO
}

Flávia Rebecca Fernandes Rocha

Universidade Estadual do Ceará (UECE)

\section{Epitácio Macário}

Universidade Estadual do Ceará (UECE)

\begin{abstract}
A PERVERSA CONCENTRAÇÃO DE RENDA VIA SISTEMA TRIBUTÁRIO
Resumo: O Estado brasileiro possui expressiva arrecadação tributária, baseada, fundamentalmente, em impostos que incidem sobre o consumo de bens e serviços. Assim, o artigo evidencia, através de dados, que isto a torna regressiva e injusta ao abarcar ricos e pobres nas mesmas proporções, ao passo que a tributação sobre o capital especulativo e 0 patrimônio, que poderia intervir fortemente na distribuição de renda, inexiste ou é muito tímida. Ressalta, também, que de forma mediada, a carga tributária de um país espelha a correlação de forças das classes em disputa e que, no caso brasileiro, tem reforçado e propulsionado a perversa concentração da renda nacional, o que aliado aos esforços de formação de superávit primário resulta em prejuízos à implementação orçamentária para financiamento e custeio de políticas públicas. Constata, por fim, que o castigo recai duplamente sobre as camadas trabalhadoras, seja pelo pagamento de impostos de consumo seja pela ausência de políticas públicas à altura das necessidades de uma sociedade dilacerada por desigualdades.
\end{abstract}

Palavras-chave: Carga tributária, orçamento, concentração de renda.

\section{THE PERVERSE CONCENTRATION OF INCOME THROUGH TAX SYSTEM}

Abstract: The Brazilian state has a significant tax revenues based primarily on taxes on the consumption of goods and services. Thus, the article shows, that it makes it regressive and unfair to encompass rich and poor in the same proportions, while the taxation of speculative capital and assets that could intervene heavily in the distribution of income does not exist or is very shy. Also highlights that, in mediated form, the tax burden of a country reflects the correlation of class forces in dispute and, in Brazil, has strengthened and propelled the perverse concentration of national income, which allied efforts to train primary surplus results in damage to budget funding for implementation and funding of public policies. At last, it shows that, the double punishment falls on the working classes is the payment of excise taxes is the absence of public policies to match the needs of a society riven by inequality.

Keywords: Tax burden, budget, concentration of income. 


\section{INTRODUÇÃO}

Aceitamos amplamente a ideia segundo a qual o padrão de acumulação de capital articulado como resposta à crise do padrão fordista/keynesiano é orientado pelo capital financeiro. Queremos dizer que, na dinâmica da totalidade da economia, o capital financeiro assumiu a condição de momento predominante e vem impondo transformações de grande monta tanto no centro como nas periferias capitalistas. Alicerçado em ampla reestruturação das formas de extração de mais-valia, o capital financeiro e suas personificações desfrutam, hoje, de imenso poder, imiscuindo sua lógica sobre os capitais investidos na produção e na urdidura das políticas macroeconômicas nacionais. A financeirização da economia dota o sistema de grande fluidez e inaudita mobilidade, confrontando as barreiras políticas, jurídicas e tecnológicas dos mercados nacionais (CHESNAIS, 2005).

Para o eminente pesquisador francês François Chesnais (1999), as instituições privadas mais poderosas do mercado financeiro mundializado são as instituições financeiras não-bancárias. 0 enorme poder político e financeiro adquirido por essas instituições repousam em dois mecanismos: 0 primeiro no âmbito dos sistemas de previdência privada por capitalização; o segundo baseia-se numa combinação articulada da distribuição desigual da renda, com a diminuição do imposto sobre rendimentos do capital e sobre as altas rendas, com 0 consequente crescimento da dívida pública - o que torna 0 próprio Estado Nacional dependente do capital financeiro.

Ora, ao diminuir a base de tributação diminui-se a receita estatal, daí a necessidade dos governos de realizarem empréstimos a taxas de juros superiores às da inflação e às do crescimento econômico, para levar a cabo esse processo, gerando um círculo vicioso em que a dívida pública se reproduz automaticamente, ano a ano. A situação é, pois, de uma ditadura dos credores que golpeia o Estado e subtrai, por meio do endividamento público e da pressão sobre as diretrizes macroeconômicas, gorda parcela da renda líquida nacional em proveito da fração de classe burguesa rentista. O golpe de Estado iniciou-se com as medidas de liberalização dos mercados de títulos públicos tomadas pelos Estados Unidos em 1979-1981, com adjudicação dos bônus do Tesouro Americano no mercado liberalizado e com a inauguração do regime financeiro de "[...] taxas de juros reais positivas.", possibilitados por uma política monetária bastante restritiva (CHESNAIS, 1999, p. 28).

Esse eldorado, onde se ajuda os rentistas a investir vantajosamente sua poupança ao invés de tributar a riqueza, estendeu-se em poucos anos para a maioria dos países capitalistas avançados como que num efeito contágio, segundo ainda Chesnais (1999). Inaugurou-se uma pragmática que instaurou uma isonomia tributária inversamente proporcional consoante com a qual os que têm maior riqueza e patrimônio contribuem menos e, ao revés, os que detêm menor capacidade contributiva são penalizados com altas taxas de tributação. É nesse contexto, marcado por políticas macroeconômicas favoráveis aos capitais rentistas e de abertura dos mercados domésticos à concorrência internacional que os setores produtivos se reestruturam, impondo altas taxas de exploração do trabalho - única forma de engendrar o colchão de mais valia que dá base à remuneração dos capitais especulativos como corretamente capturou e expressou Oliver Stone nos filmes Wall Street poder e cobiça (1987) e Wall Street - o dinheiro nunca dorme (2010).

Essas transformações se realizaram (e realizam!) no Brasil com impactos estruturais sobre a economia e a sociedade, de forma a transformar a nação em importante base para a acumulação do capital financeiro mundial, segundo pensa a economista Leda Paulani (2008). Pela mediação do endividamento público, o capital rentista impõe sua lógica sobre a política macroeconômica e, em particular, sobre a política monetária e fiscal, reforçando o caráter regressivo do sistema tributário brasileiro, e, todavia, deslocando fundos públicos da sua função precípua de financiamento de políticas sociais em favor do pagamento dos serviços e rolagem da referida 
dívida. Pressupondo este cenário, o presente artigo analisa a natureza regressiva da carga tributária praticada no País e aponta pistas para uma crítica da aplicação do fundo público na prestação de serviços pelo Estado, tentando indicar quem ganha e quem perde nessa equação.

\section{ARRECADAÇÃO DE RECEITAS TRIBUTÁRIAS E GASTOS ORÇAMENTÁRIOS: a serviço de quem?}

A Constituição de 1988 define como princípios tributários a isonomia, a universalidade, a capacidade contributiva e a essencialidade e preceitua que a tributação deve ser, preferencialmente, direta, de caráter pessoal e progressiva. Para efeito dessa reflexão, interessa fundamentalmente os conceitos de tributação progressiva e regressiva que, segundo pensa 0 estudioso Evilásio Salvador (2010), remetem à avaliação das bases de incidência dos tributos, quais sejam a renda, a propriedade, a produção, a circulação e o consumo de bens e serviços. Conforme a base de incidência, os tributos ${ }^{1}$ são considerados diretos e indiretos. Os tributos diretos incidem sobre renda e patrimônio, porque não são passíveis de transferência para terceiros, são adequados para a progressividade. Os indiretos incidem sobre a produção e o consumo de bens e serviços, sendo passíveis de transferência para terceiros, ou seja, para os preços dos produtos adquiridos pelos consumidores. 0 quanto tributos diretos $\mathrm{e}$ indiretos favorecem a progressividade ou a regressividade se depreende da seguinte afirmação de Salvador (2010, p. 50):

Um dos princípios consagrados na Carta Magna é o da capacidade contributiva, essencial para o critério de justiça, que associado aos princípios da progressividade e da seletividade, tende a assegurar uma tributação proporcionalmente maior para quem aufere rendimentos mais elevados, detém maior patrimônio e consome produtos menos essenciais. Nesse caso, os tributos diretos que incidem sobre renda e o patrimônio são os que atendem melhor a esse requisito. Já os tributos indiretos, que incidem sobre bens e serviços, independente da capacidade econômica de quem os adquire, acabam agravando a renda de pessoas e famílias que destinam maiores parcelas de seus ganhos ao consumo. As bases de incidência econômicas são: renda, consumo e patrimônio. (SALVADOR, 2010, p, 50).

No Brasil, a maior expressividade da carga tributária se dá sobre o consumo de bens e serviços, através de tributos indiretos, fazendo com que ricos e pobres contribuam com o mesmo valor. Essa situação pode se intensificar nos momentos de crise pela realização de ajustes fiscais que, via de regra, favorecem as classes economicamente dominantes pela vantagem que desfrutam quanto ao domínio do Estado na evolução da modernização conservadora (FERNANDES, 1987). Segundo Pagnussat (2011), o ajuste fiscal pode ser obtido pelo aumento das receitas, pela redução das despesas públicas ou, ainda, por uma combinação de ambas. No caso brasileiro, 0 ajuste tem sido feito preferencialmente pelo aumento da receita, com pequenos consertos focalizados nos gastos públicos, em especial pela redução dos investimentos.

0 resultado positivo na expansão da arrecadação brasileira foi obtido basicamente pela implementação de novos impostos e pelo aumento de alíquotas. A modernização da máquina tributária e 0 aumento da eficiência arrecadatória, no que pese sua importância, foram subsidiárias. Todavia, segundo análise crítica de Pagnussat (2011), as alterações no sistema tributário - que resultaram no crescimento da arrecadação - não significaram avanços na questão da justiça fiscal, da equidade, simplicidade, não cumulatividade, eficiência, flexibilidade, etc. Houve até perda de qualidade do sistema tributário brasileiro, em especial, com o aumento da regressividade e da complexidade (PAGNUSSAT, 2011).

O Brasil possui uma Carga Tributária importante, de grande destaque, inclusive em relação a países com renda per capita similar, embora não seja uma campeã mundial. Todas as sociedades dotadas de sistemas de 
proteção social estruturados, cuja provisão devém amplamente dos tributos arrecadados pelo Estado, apresentam resultados parecidos. 0 grande impacto nos gastos do Estado brasileiro, porém, são os juros e os encargos sobre a dívida que, de fato, representam a nota dissonante em termos de apropriação do Orçamento.

Pode-se verificar no Gráfico 1 que a carga tributária brasileira é alta, mas está na média de vários países do mundo, e está longe de ser a maior como querem fazer crer os analistas econômicos festejados nos meios de comunicação de massa. A partir dessa informação duas questões apresentam-se relevantes para a análise: 1- quem paga esta conta, ou seja, sobre quem recai a maior parte da tributação; e 2- qual a qualidade do retorno destes tributos através da prestação de serviços pelo Estado.

A Tabela 1, retirada do relatório anual da Receita Federal Carga Tributária Brasileira 2011, aponta a arrecadação por base de incidência nos anos de 2010 e 2011, demonstrando que $49 \%$ da arrecadação tributária brasileira se dá sobre o consumo de bens e serviços, representando $17,38 \%$ do PIB em 2011, enquanto a arrecadação sobre propriedade foi de apenas $1,31 \%$ e sobre renda $6,72 \%$ do PIB. Estes números apontam a regressividade da tributação brasileira que recai sobre a classe trabalhadora através do consumo e da folha de salário, enquanto a classe burguesa se beneficia com menores alíquotas sobre propriedade e renda, isto sem contar com as desonerações e isenções fiscais que lhes são garantidas.

\section{Gráfico 1 - Carga Tributária no Brasil e em Países da OCDE - 2010}

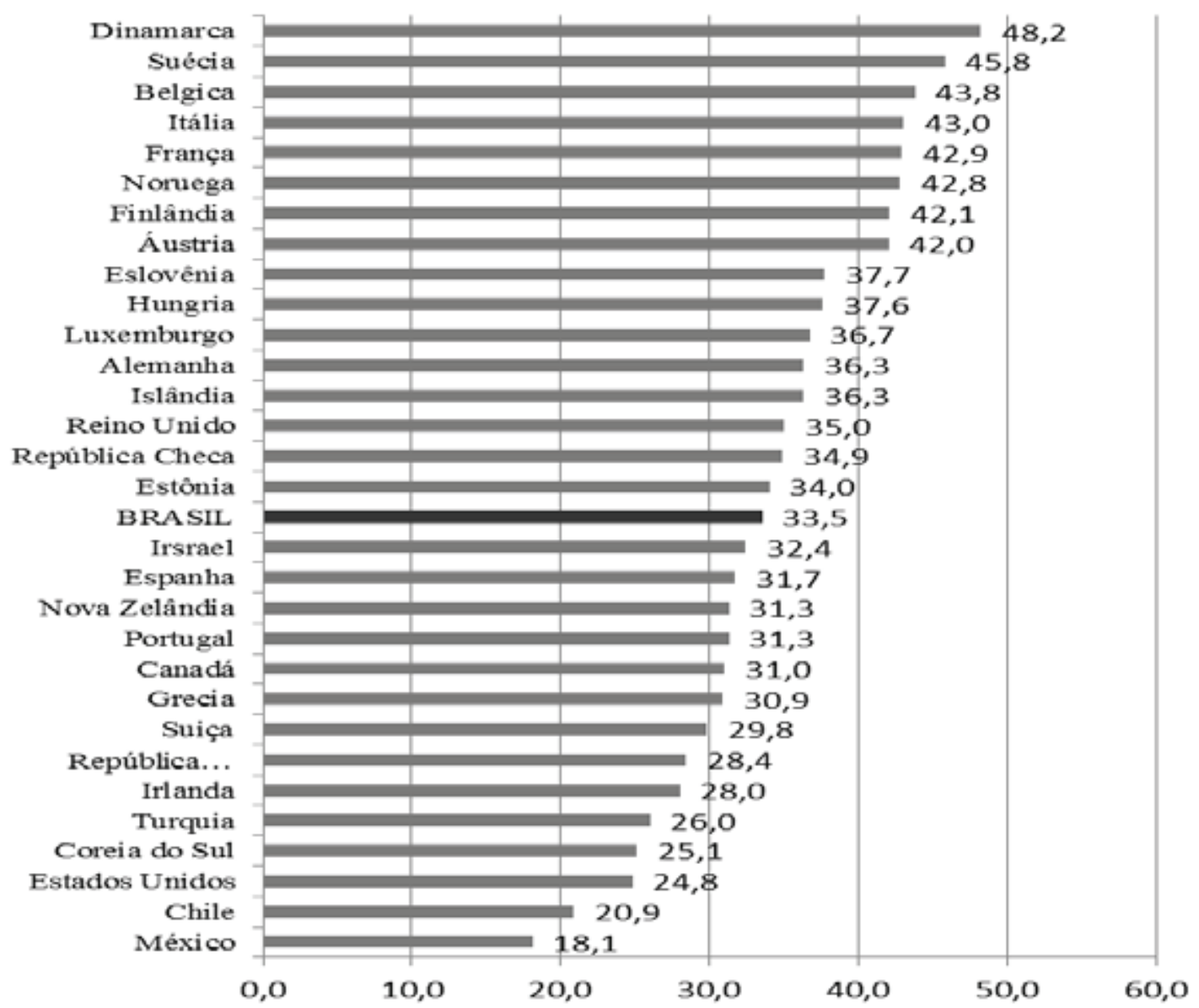

Fonte: BRASIL. Ministério da Fazenda. Carga Tributária no Brasil - 2011: análise por tributos e base de incidência. Brasilia, DF: Receita Federal, 2012. 
Tabela 1 - Carga Tributária por Base de Incidência

\begin{tabular}{|c|c|c|c|c|c|c|c|}
\hline \multirow{2}{*}{ Cód } & \multirow[t]{2}{*}{ Tipo de Base } & \multicolumn{3}{|c|}{2010} & \multicolumn{3}{|c|}{2011} \\
\hline & & $\mathrm{R} \$$ milhões & $\%$ PIB & $\%$ & R\$ milhões & $\%$ PIB & $\%$ \\
\hline 0000 & Total & $1.264 .148,52$ & $33,53 \%$ & $100,00 \%$ & $1.462 .951,95$ & $35,31 \%$ & $100,00 \%$ \\
\hline 1000 & Renda & $229.878,74$ & $6,10 \%$ & $18,18 \%$ & $278.321,37$ & $6,72 \%$ & $19,02 \%$ \\
\hline 2000 & Folha de salário & $330.456,24$ & $8,76 \%$ & $26,14 \%$ & $376.849,13$ & $9,10 \%$ & $25,76 \%$ \\
\hline 3000 & Propriedade & $47.433,83$ & $1,26 \%$ & $3,75 \%$ & $54.143,86$ & $1,31 \%$ & $3,70 \%$ \\
\hline 4000 & Bens e Serviços & $628.669,30$ & $16,67 \%$ & $49,73 \%$ & $720.098,58$ & $17,38 \%$ & $49,22 \%$ \\
\hline 5000 & Transações financeiras & $26.553,03$ & $0,70 \%$ & $2,10 \%$ & $32.077,10$ & $0,77 \%$ & $2,19 \%$ \\
\hline 9000 & Outros & $1.157,38$ & $0,03 \%$ & $0,09 \%$ & $1.461,92$ & $0,04 \%$ & $0,10 \%$ \\
\hline
\end{tabular}

Fonte: (BRASIL, 2012).

Para enfrentar o desequilíbrio fiscal do final dos anos 1990 e início da década de 2000, o governo empreendeu um esforço fiscal sem precedentes, via aumento da arrecadação, conforme já apontado. Privilegiou a criação e fortalecimento das contribuições ${ }^{2}$ em detrimento de impostos considerados de melhor qualidade, como 0 Imposto de Renda (IR), em razão de este último ser partilhado com os estados e municípios, enquanto as contribuições não 0 são. Porém, para poder utilizar a verba ampliada através destas contribuições (receitas vinculadas não contingenciáveis) foi criada a DRU (Desvinculação de Receitas da União $^{3}$ como possibilidade de contingenciamento (PAGNUSSAT, 2011).

0 resultado foi a obtenção de expressivos superávits primários ${ }^{4}$ ao longo da década e uma estabilização da economia. Sem nos delongar no fato de que tais poupanças fiscais significam menos investimento do Estado e menos disponibilidade para custear políticas sociais, realçamos que, no seu conjunto, estes fenômenos implicaram em mudança no perfil do sistema tributário. Com efeito, amplificaram-se as distorções no setor produtivo e ampliou-se a participação de tributos sobre o consumo e, em especial, os cumulativos, ou seja, tributos que incidem em mais de uma etapa da circulação de mercadorias sem que na posterior seja abatido ou compensado o montante pago na etapa anterior, penalizando, por esta via, os mais pobres, que passaram a arcar com uma carga tributária maior.

Em síntese, houve uma piora qualitativa do sistema tributário brasileiro, mas com significativo aumento da sua capacidade arrecadadora. $\mathrm{O}$ aumento da participação dos impostos indiretos (PIS, Cofins, IPI, ICMS, etc.) na carga tributária brasileira levou a um aumento do peso dos impostos sobre os mais pobres, dado que tais impostos são transferidos para o preço dos produtos e serviços, deslocando, assim, o ônus para os consumidores indiferentemente do segmento de classe a que pertençam.

Os estudiosos do tema defendem que 0 ideal seria um aumento nos impostos diretos que não podem ser repassados para os consumidores, pois incidem diretamente sobre renda e patrimônio, não por acaso, são os menores no Brasil. Nesta forma de tributação, considerada progressista, o pagamento é proporcional à renda ou patrimônio, ou seja, os mais ricos pagam mais. São impostos que criam bases e possibilidades de uma política distributiva eficiente na redução das desigualdades de renda.

Segundo Salvador (2010) as principais mudanças no perfil da tributação do país foram realizadas no governo Fernando Henrique Cardoso e contribuíram para a concentração de renda como:

a) Desoneração da tributação do lucro das empresas por meio da redução da alíquota do Imposto de Renda de Pessoa Jurídica (IRPJ) de 25\% para $15 \%$ (Lei $n^{0}$ 9.249/95) para os 
optantes da forma de tributação denominada lucro real;

b) Eliminação da alíquota de $35 \%$ do Imposto de Renda de Pessoa Física, reduzindo a progressividade $\mathrm{e}$ aumento do número de declarante de IR pela não correção da tabela, fazendo com que os trabalhadores de mais baixa renda fossem tributados (Lei $n^{0}$ 9.430/96);

c) Desde 1998, alíquota mínima do IR passou de $5 \%$ para $7,5 \%$, e a máxima foi reduzida em mais da metade, de $60 \%$ para $27,5 \%$ (Lei $n^{\circ}$ 9.532/97).

Para Salvador (2010), além dos benefícios que as mudanças trouxeram para 0 capital, que passou a pagar menos tributos, as pessoas físicas de maior renda, sobretudo profissionais liberais, passaram, a partir das mudanças realizadas, a constituírem Pessoas Jurídicas (PJ). Em vez de relação de contrato de trabalho regido pela Consolidação das Leis Trabalhistas (CLT), o empregado monta uma empresa (PJ) que presta serviço para seu antigo empregador; em vez de salário, ele terá lucro distribuído, agora isento de imposto de renda. Um mecanismo perverso de concentração de renda via sistema tributário que expressa, no plano da política tributária, a correlação de forças amplamente favorável aos capitalistas e às elites ricas do País. Não é demais repisar o fato de que a estrutura tributária reflete os conflitos de classes em torno da formação e distribuição do fundo público. Como assevera o professor Evilásio Salvador (2010), cada mudança importante no equilíbrio das forças políticas em disputa é registrada pela estrutura tributária, pois esta é uma forma particular do sistema de classe.

O mesmo se pode afirmar do fundo público que tem no sistema tributário sua fonte de recursos, razão porque podemos afirmar que, no Brasil, este fundo é amplamente financiado pelos trabalhadores assalariados e pelas classes de menor poder aquisitivo através de uma tributação regressiva. Como tal, o fundo público é objeto de disputa das classes fundamentais e sua distribuição e alocação dependem da correlação de forças de tais classes. Numa época em que impera a lógica do superávit primário e a renúncia fiscal em favor das empresas, as classes burguesas e proprietárias saem ganhando na distribuição desse fundo. Elaine Behring fornece importante chave teórica para a compreensão da natureza do fundo público e da disputa que o cerca:

\begin{abstract}
O fundo público se forma a partir de uma punção compulsória - na forma de impostos, contribuições e taxas da mais-valia socialmente produzida, ou seja, é parte do trabalho excedente que se metamorfoseou em lucro, juro ou renda da terra e que é apropriado pelo Estado para o desempenho de múltiplas funções. $O$ fundo público atua na reprodução do capital, retornando, portanto, para seus segmentos especialmente nos momentos de crise; e na reprodução da força de trabalho, a exemplo da implementação das políticas sociais (BEHRING, 2010, p. 20).
\end{abstract}

A crise que, a partir de 2008, pipocou no coração do sistema financeiro mundial (Wall Street) e na União Europeia, deu clara demonstração de como o fundo público é apropriado e utilizado no sentido de revitalizar o capital e salvaguardar seus lucros e as rendas dos grandes investidores. No torvelinho da crise, as instituições financeiras recorreram todas ao Estado e lograram a transferência de vultosas somas do fundo público com o fim de restaurar a confiança nos mercados. A velha lei do valor desdobrada às últimas consequências por Karl Marx é assim chamada à ordem, pois segundo Husson (2008 apud BEHRING, 2010, p. 29)

Os títulos financeiros são um direito em conta sobre a mais-valia produzida. Enquanto não se exerce esse direito, tudo segue sendo virtual. Porém, quando ele se faz valer, se descobre que está submetido à lei do valor, o que consiste em dizer simplesmente que não se pode distribuir mais riqueza do que a que realmente foi produzida. 
A base material mais profunda da crise, portanto, está localizada na defasagem crescente entre um restrito poder de consumo, centrado no consumo de luxo fortemente destrutivo, frente a uma expansão crescente da produção.

A lógica do capital financeiro que tende sempre para a criação de imensas somas de valores fictícios acentua as tendências de crise do capitalismo que passa a exigir do Estado mais segurança nas operações, diminuindo os riscos para os credores. Como exemplo, temos a Lei federal no 101/2000 (Lei de Responsabilidade Fiscal - LRF) que, segundo Leda Paulani (2008), tem como propósito estabelecer uma hierarquia dos gastos públicos que coloca em primeiríssimo e indisputável lugar o credor financeiro, em detrimento da alocação de recursos com fins distributivos e da viabilização de investimentos públicos. No mesmo sentido, Evilásio Salvador (2010) argumenta que a LRF e 0 ajuste fiscal implicaram em resultados positivos nas contas governamentais, cujos saldos positivos têm sido canalizados para o pagamento de juros e amortizações da dívida pública. Por outro lado, o contingenciamento orçamentário é um artifício que tem por fim assegurar 0 cumprimento das metas de superávit primário impostas pelos credores da dívida. Isto prova o direcionamento da política tributária e fiscal em prol dos bancos e demais instituições portadoras do capital rentista.

O Brasil mantém uma alta taxa de juros interna e quanto maior os juros, maior 0 superávit requerido para manter a dívida pública estável em proporção do Produto Interno Bruto (PIB). A partir de 1999, começa o esforço de geração de superávits primários consistentes ${ }^{5}$, mas em um contexto de gastos públicos crescentes e de orçamento altamente engessado pelas despesas obrigatórias e elevada vinculação de receitas a gastos.

A chamada "rolagem" da dívida ou refinanciamento não significa mera troca de títulos velhos por novos, mas novas operações em novas condições. A CPI da Dívida revelou que antes de cada vencimento de obrigações da dívida é feita nova oferta de títulos no mercado, por meio de "dealers" (grandes bancos que tem prioridades na negociação de títulos), ficando o Tesouro sujeito à chantagem do mercado financeiro, que só compra os títulos quando as taxas de juros se elevam até onde desejam os bancos (FATORELLI, 2013, p. 4, grifos do autor).

Dito de outro modo, a manutenção das altas taxas de juros internas é uma necessidade imposta pelos credores, possuidores de títulos da dívida pública, pois ela influencia diretamente o crescimento da dívida, aumentando os lucros. É o Estado e 0 fundo público postos a serviço

[...] de uma lógica econômica em que o dinheiro entesourado adquire, em virtude de mecanismos do mercado secundário de títulos e da liquidez, a propriedade 'miraculosa' de 'gerar filhotes'." (CHESNAIS, 2005 , p. 50 , grifos do autor).

Em seu estudo, Tatiana Brettas (2012) põe às claras o tamanho da dívida pública e dos gastos com o pagamento de juros dos cinco países mais endividados e do Brasil. A Tabela 2 foi tomada de empréstimo do artigo da pesquisadora com o fim de demonstrar os custos astronômicos da dívida para o Brasil

Tabela 2 - Dívida total e gastos com o pagamento de juros em 2010 e 2011 (em \% do PIB)

\begin{tabular}{ccccc}
\hline País & \multicolumn{2}{c}{$\mathbf{2 0 1 0}$} & $\mathbf{2 0 1 1}$ \\
\cline { 2 - 5 } & Dívida total/PIB (\%) & $\begin{array}{c}\text { Pagamento de juros } \\
\text { da dívida/PIB }(\%)\end{array}$ & $\begin{array}{c}\text { Dívida } \\
\text { total/PIB }(\%)\end{array}$ & $\begin{array}{c}\text { Pagamento de juros } \\
\text { da dívida/PIB (\%) }\end{array}$ \\
Japão & 199 & 1,43 & 209,20 & 0,80 \\
Grécia & 143 & 5,47 & 154,80 & 6,50 \\
Itália & 119 & 4,53 & 119,80 & 4,20 \\
Irlanda & 95,7 & 3,20 & 112,60 & 3,20 \\
Portugal & 93 & 3,04 & 103,50 & 3,40 \\
Brasil & 59 & 5,10 & 57,40 & 4,90 \\
\hline
\end{tabular}

Fonte: Economist Intelligence Unit (EIU), divulgado pela BBC Brasil, citado por: BRETTAS, Tatiana. Dívida pública: uma varinha de condão sobre os recursos do fundo público. In: SALVADOR, Evilásio et al (Orgs.). Financeirização, Fundo Público e Política Social. São Paulo: Cortez. 2012. 
que, embora tenha endividamento menor que os casos citados, despende muito mais recursos no pagamento de juros.

O Japão, por exemplo, tinha uma dívida equivalente a mais de duas vezes o seu PIB em 2011 (209,20\%), e gastou menos de $1 \%$ do PIB com pagamento de juros. O Brasil, que está em $12^{\circ}$ segundo lugar no ranking dos países mais endividados, é o segundo país que mais gasta com juros da dívida em relação ao PIB, ficando atrás somente da Grécia, que vem enfrentando uma profunda crise econômica. 0 percentual da dívida externa brasileira sobre o PIB alcançou $(57,4 \%)$ e os juros da dívida pagos sobre 0 PIB (4,9\%), em 2011.

Resta ainda observar que 0 beneficiamento do capital financeiro por meio da dívida pública brasileira foi reforçado com a abertura de espaços novos de acumulação nos serviços sociais, dentre os quais a saúde, a previdência, a educação, a segurança. Concorreram para isto as privatizações das empresas de serviços públicos, a abertura do mercado da saúde e da segurança, o insidioso financiamento de capitais privados na esfera da educação superior, as reformas da previdência ${ }^{6}$ com 0 desmantelamento do sistema de previdência por repartição ${ }^{7}$ para a criação dos fundos de pensão. Foram estas transformações que orientaram as políticas governamentais de favorecimento do capital portador de juros, pois, para este, não há melhor investimento do que as indústrias de serviços públicos privatizados, que mantêm consumidores cativos. (CHESNAIS, 2005, p. 62).

\section{CONCLUSÃO}

0 aumento da participação dos impostos indiretos combinado com a baixa tributação das grandes rendas e do patrimônio resulta em favorecimento dos mais ricos e na penalização dos mais pobres. Assim, já do ponto de vista da arrecadação, o sistema tributário brasileiro não favorece a justiça social ao reforçar as profundas e históricas desigualdades de renda que acompanham a modernização conservadora à brasileira. Por seu turno, a alocação das rendas tributárias revela também, a mesma natureza regressiva e injusta em face do contingenciamento de verbas das políticas sociais para cumprir metas de superávit primário exigido para a quitação de juros e amortizações da dívida pública. Neste caso, vultosas fatias do fundo público são entregues diretamente aos credores do Estado, retroalimentando a financeirização da economia.

Segundo entendemos e na esteira do pensamento de pesquisadores da área, isso dá provas de que os sistemas tributários e orçamentários constituem locus de disputa política perpetrada pelas classes ou segmentos de classe. Com efeito, apenas uma olhadela nos relatórios da Auditoria cidadã da dívida revela que, por exemplo, no ano de 2013, o Orçamento Geral da União reservou nada menos que $40,30 \%$ de recursos para pagamento de juros da dívida - que alcançou a bagatela de 718 bilhões de reais. A mesma peça orçamentária reservou $4,29 \%$ para gastos com saúde, $3,70 \%$ para a educação e $3,41 \%$ para a assistência social ${ }^{8}$.

Conclui-se, pois, que mesmo não sendo - lócus resolutivo da luta entre as classes fundamentais, as disputas políticas em torno do sistema tributário, do orçamento e do fundo público constituem importante mediação da luta mais geral que se desenrola na sociedade. Por esta razão, são espaços que devem ser tensionados pelas classes trabalhadoras na busca por justiça social.

\section{REFERÊNCIAS}

BEHRING, Elaine Rossetti. Crise do capital, fundo público e valor. In: BOSCHETTI Ivanete et al (Orgs.). Capitalismo em crise, política social e direitos. São Paulo: Cortez, 2010.

BRASIL. Ministério da Fazenda. Carga Tributária no Brasil - 2011: análise por tributos e base de incidência. Brasília, DF: Receita Federal, 2012.

BRETTAS, Tatiana. Dívida pública: uma varinha de condão sobre os recursos do fundo 
público. In: SALVADOR, Evilásio et al (Orgs.). Financeirização, fundo público e política social. São Paulo: Cortez, 2012.

CHESNAIS, François (Org.). A finança mundializada. Tradução de Rosa Maria Marques e Paulo Nakatani. São Paulo: Boitempo, 2005.

Tobin or not tobim? Tradução de Maria Tereza Van Acker. São Paulo: Editora UNESP: ATTAC, 1999.

FATORELLI, Maria Lúcia. Números da Dívida. [S. I.: s. n.], 2012. Disponível em:<http://www.auditoriacidada.org.br/marialucia-fatorelli-banqueiros-capturaram-o-estadobrasileiro>. Acesso em: 1 jan. 2014.

FERNANDES, Florestan. A revolução burguesa no Brasil: ensaio de interpretação sociológica. 3. ed. Rio de Janeiro: Ed. Guanabara, 1987.

PAGNUSSAT, José Luiz. O financiamento da estabilidade macroeconômica e da expansão das políticas sociais no Brasil. In: VAZ, Flávio; MARTINS, Floriano (Orgs). Orçamento e políticas públicas: condicionantes e externalidades. Brasília, DF: ANFIP, 2011.

PAULANI, Leda. Brasil delivery: servidão financeira e estado de emergência econômico. São Paulo: Boitempo, 2008.

SALVADOR, Evilásio. Fundo público e seguridade social no Brasil. São Paulo: Cortez, 2010.

\section{NOTAS}

${ }^{1}$ Nos termos do art. $3^{\circ}$ do Código Tributário Nacional, Tributo é toda prestação pecuniária compulsória, em moeda ou cujo valor nela se possa exprimir, que não constitua sanção de ato ilícito, instituída em lei e cobrada mediante atividade administrativa plenamente vinculada. Ou seja, tributo é uma prestação que o contribuinte dá ao Estado, de forma obrigatória, em dinheiro (regra geral) ou em títulos ou bens (exceções), que não é uma punição ou pena, criada através de lei e cobrada pela administração pública (fisco). Os tributos são divididos em: impostos, que considera os recursos de quem paga; taxas, paga-se pelo exercício do poder de polícia ou quando se utiliza serviços públicos (taxa de coleta de lixo, de iluminação pública, dentre outros); e as contribuições em que a alíquota é fixa, não deve variar com os recursos da pessoa que paga (Cofins, CSLL, PIS, dentre outros).

2 As contribuições sociais são recursos custeados por empresas e trabalhadores e constituem, no Brasil, a principal fonte de financiamento da seguridade. Essa base de custeio não atende plenamente ao objetivo da equidade e tem caráter regressivo. Os trabalhadores de menor renda têm uma contribuição proporcionalmente maior que aqueles de renda mais elevada. Já as contribuições dos empregadores, em geral, são repassadas aos preços de produtos e serviços, onerando toda a coletividade, e podendo constituir um tributo sobre o consumo (SALVADOR, 2010).

3 Em 1993 ocorreu no Brasil à criação do chamado Fundo Social de Emergência (FSE), permitindo a desvinculação de $20 \%$ das receitas arrecadadas pela União, seguindo as orientações do Banco Mundial e do Banco Internacional de Desenvolvimento (BID). Este fundo assumiu uma função de desviar recursos da área social para o interior do orçamento fiscal à disposição do Ministério da Fazenda com vistas ao equilíbrio das contas públicas, contribuindo para a estabilidade econômica. O FSE foi substituído por um nome mais apropriado, nos exercícios financeiros de 1994 e 1995: Fundo de Estabilização Fiscal (FEF); depois por Desvinculação de Renda da União (DRU) prevista para acabar em 2011, porém já prorrogada sua vigência até 2015 (SALVADOR, 2010).

4 O resultado primário é a diferença entre receitas não financeiras arrecadadas no exercício fiscal e as despesas não financeiras arrecadadas no exercício do mesmo período, previstas no Orçamento da União.

${ }^{5}$ A crise financeira dos países asiáticos, em 1997, já mostrava os riscos do financiamento do déficit em conta corrente com capital especulativo, e a moratória russa, de agosto de 1998, acentua os movimentos especulativos contra o real. Acelera-se a fuga de capitais e o Banco Central eleva a taxa de juros a $49,75 \%$ ao ano, em setembro de 1998, instalando-se uma grande crise no Brasil, com forte desequilíbrio das contas externas e um cenário de insustentabilidade da dívida pública, com riscos de iliquidez e insolvência. O governo recorre ao Fundo Monetário Internacional (FMI), institui o Programa de Estabilização Fiscal (PEF) e adota a política macroeconômica de metas de inflação, câmbio flutuante e superávits primários (PAGNUSSAT, 2011).

6 Política pública de caráter contributivo faz parte do tripé da Seguridade Social, nesta a participação dos trabalhadores foi universalizada, seja como 
contribuinte obrigatório ou como contribuinte facultativo. O sistema previdenciário comporta 0 Regime Geral de Previdência Social (RGPS) e os Regimes Próprios de Previdência de Servidores Públicos (RPPS). O primeiro regido pelo Instituto Nacional de Seguro Social (INSS), para contribuintes da iniciativa privada; e o último para servidores ocupantes de cargos efetivos e/ou militares. Em paralelo aos regimes básicos, há o complementar, ou planos de previdência privada.

70 regime de repartição é por definição produtivista (interessam-lhe emprego), enquanto 0 regime de capitalização é rentista (interessam-lhe juros reais elevados e ativos fixos). Os fundos de pensão funcionam como braço auxiliar da dívida pública, no papel de retirar da esfera da acumulação produtiva parcelas substantivas de renda real que poderiam, de outro modo, transformar-se em capital produtivo. Farão assim, indiretamente, pela via voluntária das contribuições previdenciárias, aquilo que o Estado faz diretamente pela via da impositiva dos tributos (PAULANI, 2008, p. 46).

8 Disponível em:<http://www.auditoriacidada.org.br/epor-direitos-auditoria-da-divida-ja-confira-o-grafico-doorcamento-de-2012/>.

Flávia Rebecca Fernandes Rocha

Assistente Social

Mestranda em Serviço Social, Trabalho e Questão

Social

Bolsista CAPES da Universidade Estadual do Ceará (UECE)

E-mail: rebeccarocha.as@gmail.com

\section{Epitácio Macário}

Professor Universitário

Doutor em Educação pela Universidade Federal do Ceará (UFC)

Servidor Público da Universidade Estadual do Ceará (UECE)

E-mail: epitacio.macario@uece.br

\section{Universidade Estadual do Ceará - UECE}

Avenida Paranjana, 1700 - Campus do Itaperi, Fortaleza/CE

CEP: $60740-000$ 